\title{
Effect of discontinuities on the stability of rock blocks in tunnel
}

\author{
Hamed A. Keykha*, Bujang B. K. Huat, Thamer A. Mohammad Ali and Hossien Moayedi \\ Department of Civil Engineering, Faculty of Engineering, UPM, Malaysia.
}

Accepted 6 March, 2012

\begin{abstract}
This paper presents the results of an investigation that was carried out using important parameters, such as discontinuities in forming rock block and instability in tunnel. Discontinuities like bedding and joints are one of the most important factors when compared with parameters, such as engineering features of rock mass. In this review, numerous features like rock quality designation (RQD), rock classification (RMR), stress and strain and distributions of discontinuities in a sample tunnel were evaluated. However, most of them were suitable in the tunnel, but because of the creation of more intersection points in critical zone, the movement of blocks in tunnel roof and wall of the tunnel are possible. It also demonstrates simple factors such as step-over joints in rock mass, having important effect in instability.
\end{abstract}

Key words: Step-over joint, rock quality designation, rock mass rating, stress and strain, discontinuity significant index (DSI).

\section{INTRODUCTION}

For the stability analysis of tunnels, there are so many parameters which should be taken into account. The parameters may have the same effects in stability and/or different action. The most important of these parameters are rock mass strength, geology structures, main stress and strain, rock classification, discontinuities, etc. All of these may have an impact on tunnel stability. If some are suitable and only just one is troubled, it can be due to instability in tunnel. It is important to regard all parameters from less significant to the most important.

One of the most serious problems in tunnel excavation is the accidental falling of rock blocks that are formed by the intersection of the tunnel surface and discontinuities in the rock mass (Lee and Song, 1998). The discontinuities are structures, such as bedding planes and joints with usually several sets in very different directions which separate the rock mass into discrete but interlock pieces (Jaeger and Cook, 1979). The rock blocks are easy to slide along structural plan, because of the low shear and tensile strength. The most common

*Corresponding author. E-mail: hamed_geology@yahoo.com. types of failure are those involving wedges falling from the roof or sliding out of the sidewalls of the openings. When a free face is created by the excavation of the opening, the constraint from the surrounding rock is removed. The analysis of rock blocks is detected by block theory. Block theory is presented by Goodman and Shi (1985) as an effective method in stability analysis of rock engineering. Block theory states fractures in rock mass to be planed, analyzed on the basis of potentiality of removable blocks and key blocks for achieving the desirable reinforcement stability.

In this theory, features of key blocks are estimated. There are several blocks in the excavation section (Figure 1).

1) Type I being moveable.

2) Type II having key potential to move.

3) Type III has no movement because of its position in basement.

4) Type IV has no movement because of blocking with around blocks.

5) Type V, a jointed block without any free space in rock mass (Hammett and Hoek, 1981).

The key blocks (I and II) described as instable block in 


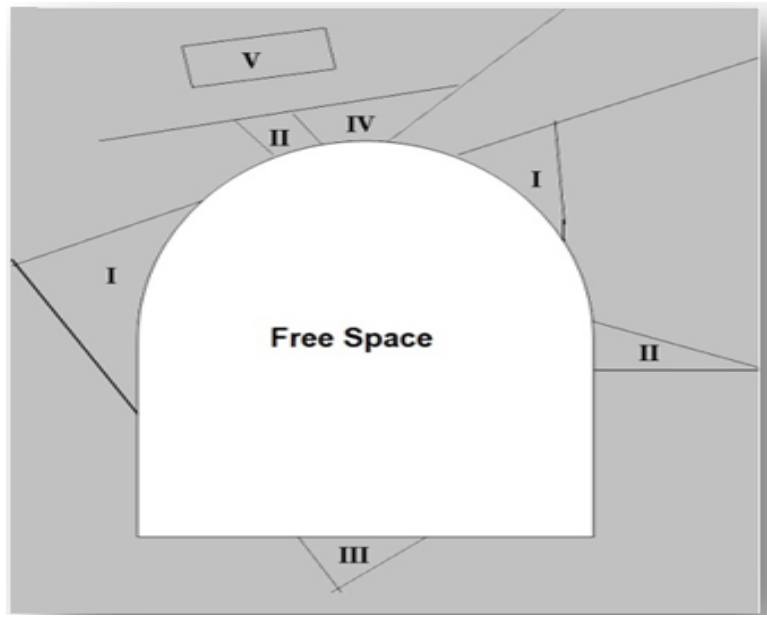

Figure 1. Type of blocks around the excavation section.

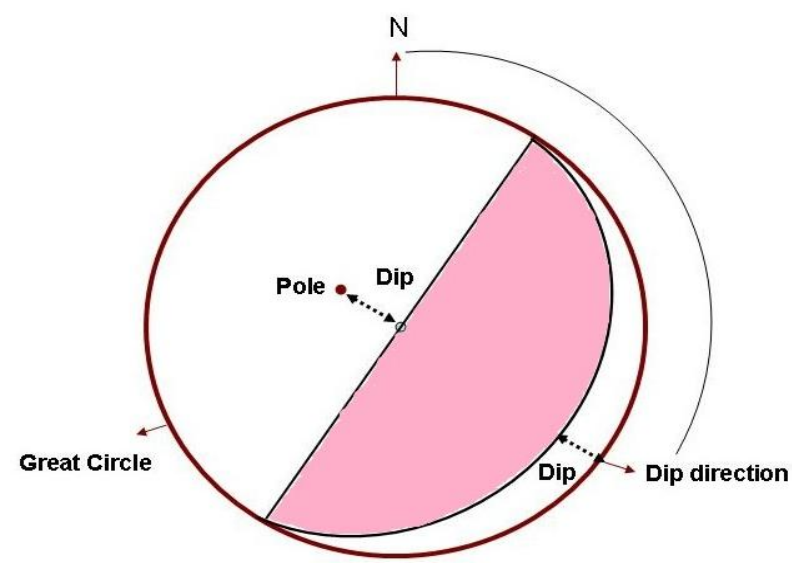

Figure 2. Two dimensional representations of planes and poles in horizontal plane.

rock mass should be taken into great consideration. These blocks are evaluated by kinematic method.

Chan and Goodman (1987) calculated the average number and volume removable blocks using the Baecher disk model (Baecher et al., 1977). Mauldon (1993) studied the change in joint pyramids according to the variation of joint set orientations. Hoerger and Young (1990) applied the Baecher disk model with a bivariate normal distribution of joint orientation to the analysis of block occurrence around a tunnel.

\section{METHODOLOGY}

The kinematic analysis of rigid blocks, are used by stereographic projection. Every block is produced with at least 4 planes which crossed each other. In general, the block in rock mass is created by 3 discontinuities and one free face which may be the excavation surface. The blocks depend on their positions being stable or instable. When the direction of planes set in free face, the block is instable. It can move as sliding and falling.

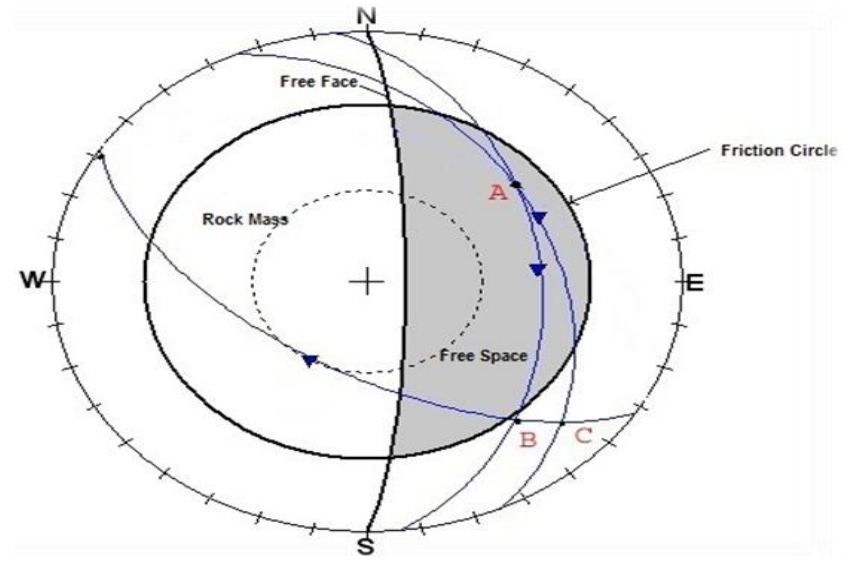

Figure 3. The relationship of planes with friction circle in free face of rock mass.

For the analysis of block stability, the position needs to be defined for discontinuities and features such as friction angle of planes. Every discontinuity plane is detected by Dip and Dip direction which is evaluated by geological compass. Then, the data are analyzed by a stereographic method. In this way, an analysis of three dimensional data can be carried out in two dimensions as lines and poles to a horizontal surface (Figure 2). Also, the friction angle is estimated by test on rock sample.

The blocks which are instable and portable, possess planes with potential movement. When the dip plane move direct on free face, the plane can slide. For example, there are 3 lines of intersection in a tetrahedral block. If lines are put in free space, they could have the possibility to move and enjoy more discontinuity significant index (DSI).

Figure 3 shows three discontinuities in a rock mass along with free face. The free face is defined by the amount of friction angle measured by shear test of rock sample. The dark zone is free space or critical zone illustrated by relationship between dip of slope or excavation face $(\psi)$ and friction angle $(\varphi)$. A point is the line of intersection between two planes, which are put in critical zone. It can slide in free face direction. But $B$ and $C$ points are not in critical zone and may have possibility to move.

\section{Case study for stability analysis in a tunnel of IRAN}

To analyze the stability in a rail way tunnel in the eastern part of Iran, so many features have been studied. The tunnel had operated in sandstone mass with vertical bedding that had about $250 \mathrm{~m}$ length (Figure 4). The significant parameters studied were rock quality designation (RQD), rock mass classification (RMR), discontinuities, stress, strain and strength of rock mass. The tunnel collapsed in 150 to $160 \mathrm{~m}$ of its length. The results of this research are illustrated as the following.

\section{RQD evaluation}

RQD is counted by joint sets (discontinuities) per unit volume $J_{v}$. Table 1 shows the estimated RQD in every $25 \mathrm{~m}$ of length of the tunnel picked up from the wall and roof. The RQD is counted with Equation 1. This evaluation indicates that the RQD is more than 80 and condition of rock mass is desirable.

$$
R Q D=115-3.3 J_{v}
$$




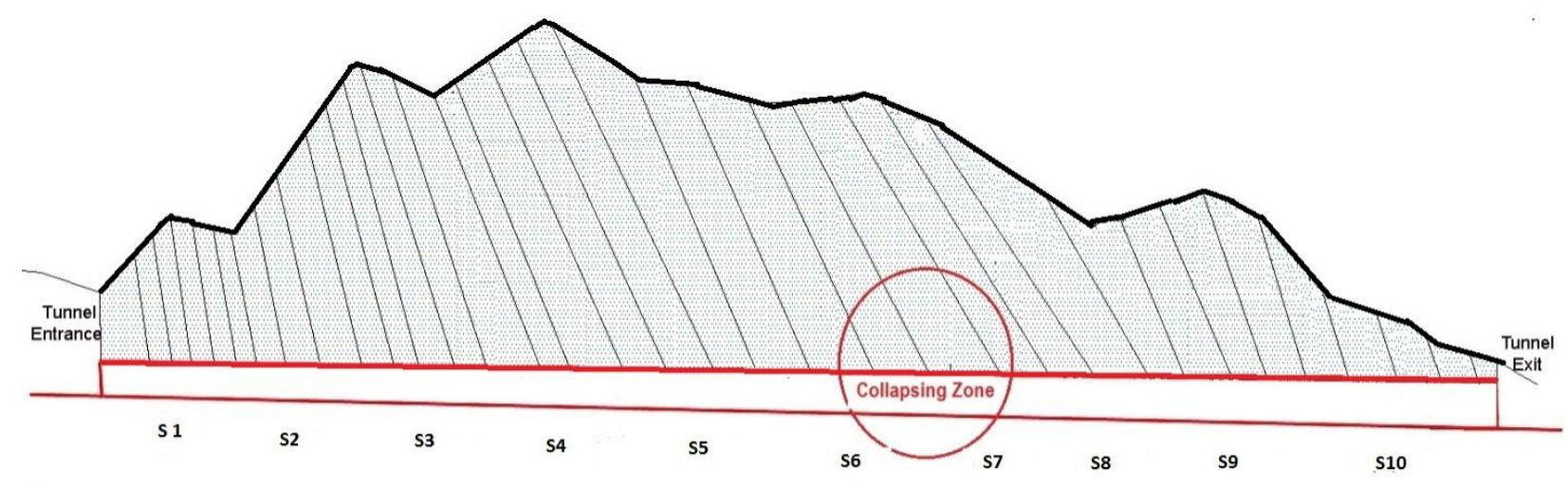

Figure 4. The tunnel with vertical bedding in sandstone mass.

Table 1. Estimated RQD in every $25 \mathrm{~m}$ length of tunnel.

\begin{tabular}{|c|c|c|}
\hline Section & $I_{v}$ & $R Q D$ \\
\hline 1 & 8 & 89 \\
\hline 2 & 9 & 85 \\
\hline 3 & 8 & 89 \\
\hline 4 & 10 & 82 \\
\hline 5 & 10 & 82 \\
\hline 6 & 10 & 82 \\
\hline 7 & 11 & 78 \\
\hline 8 & 9 & 85 \\
\hline 9 & 7 & 91 \\
\hline 10 & 10 & 82 \\
\hline Total & & 85 \\
\hline Description & & Very good \\
\hline
\end{tabular}

\section{Rock mass classification (RMR)}

The classification of rock mass of the tunnel has been done on the basis of RMR presented by Bieniawski (1989). In this study, several features like RQD, unaxial strength, groundwater conditions, spacing, condition and orientation of discontinuities, have been noticed. Table 2 shows the average achieved RMR for the tunnel. The assessment states that the condition of rock mass is appropriate for the purpose of tunneling.

\section{Stress and strain in rock mass}

Induced stresses as a result of the weight of overlying strata are relatively impressive. The weight of the vertical column of rock resting on this element is the product of the depth and the unit weight of the overlying rock. This stress is estimated from the simple relationship as follows:

$$
\sigma_{v}=\gamma z
$$

where $\sigma_{w}$ is the vertical stress, $\gamma$ is the unit weight of the overlying rock and $z$ is the depth below the surface (Hoek, 2006). These stresses as sample are estimated in collapsing zone. Figure 5 shows a graph of vertical stresses from ground surface to the floor of the tunnel in about $50 \mathrm{~m}$.

The three-dimensional analysis of stresses and displacements in the surrounding rock mass in this tunnel has been carried out. The stress distribution in the rock mass indicated in a cross section in collapsing zone (Figure 6). It seems that, because of the fact that there is lack of water table and good rock condition, the induced stress after tunneling is suitable in rock mass causes the deformation or strain in rock mass. Evaluations of strain in rock mass can be interpreted by the displacement around the tunnel. As shown in Figure 7 , the displacement in this tunnel is too small $(0.54$ $\mathrm{mm})$.

\section{Stability analysis of rock block}

In the first step, the features of joint sets and discontinuities are collected. In this survey, about two types of joint and bedding are recognized. There are numbers of fractures between bedding, named step-over fractures. The step-over fractures are joints in the left or right at the bedding contact. In fact, the strength of bedding contacts controls the type of resulting fracture intersection. Fracture termination is favored at very weak bedding contacts, whereas fractures propagate straight through strong contacts. Most sedimentary contacts will fall between these two end-members. Fracture termination is more likely under conditions of shallower burial depth, lower effective layer-parallel tension and fluid-driven propagation, rather than equivalent remote layer-parallel tension. Thicker beds and greater effective layer-parallel tension may produce greater amounts of step-over than thinner beds and more compressive layers (Cooke and Underwood, 2001). The fractures often have sliding that may give rise to block movement (Figure 8).

In the second step, the data are estimated by computer program for the tunnel wall and roof. As the analysis of rock wedges indicates, there are several portable blocks in the wall and roof. Figure 9 shows some planes with intersection points in tunnel walls located in critical zone. These blocks can have possibility to slide around the wall. In other words, it will probably split out as wedge blocks. In addition, the evaluation of stability in tunnel roof displays that toppling is created by intersection points of discontinuities in critical zone (Figure 10). 
Table 2. The average of RMR for the tunnel.

\begin{tabular}{lllc}
\hline & Parameter & Value & Rating \\
\hline 1 & Unaxial strength & $79.8 \mathrm{Mpa}$ & 7 \\
2 & RQD & 85 & 17 \\
3 & Spacing of discontinuity & $30 \mathrm{~cm}$ & 10 \\
4 & Condition of discontinuity & Slightly rough surfaces (Separation $<1 \mathrm{~mm}$ ) & 25 \\
5 & Orientation of discontinuity & Favorable & -2 \\
6 & groundwater conditions & Completely dry & 15 \\
Total & & 72 & \\
Class No. & & II & \\
Description & & Good rock \\
\hline
\end{tabular}

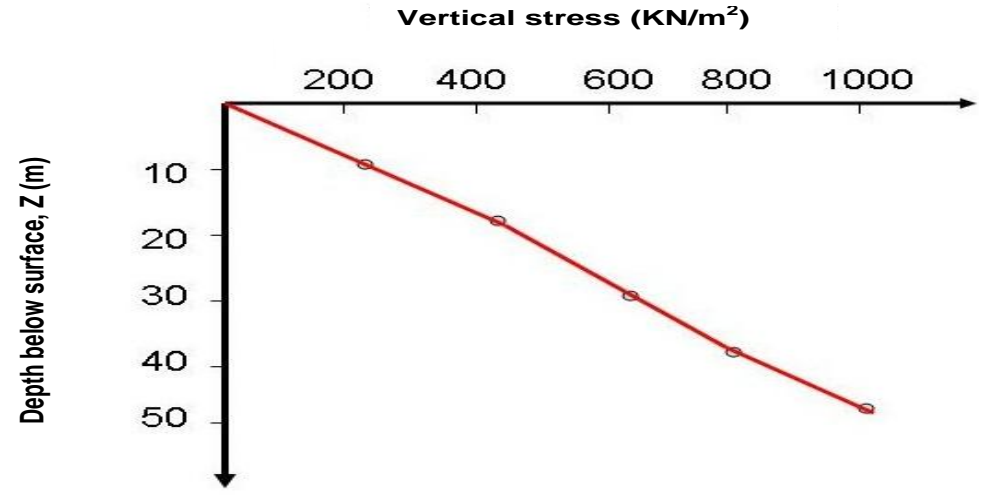

Figure 5. The relationship between vertical stress and depth above the tunnel.

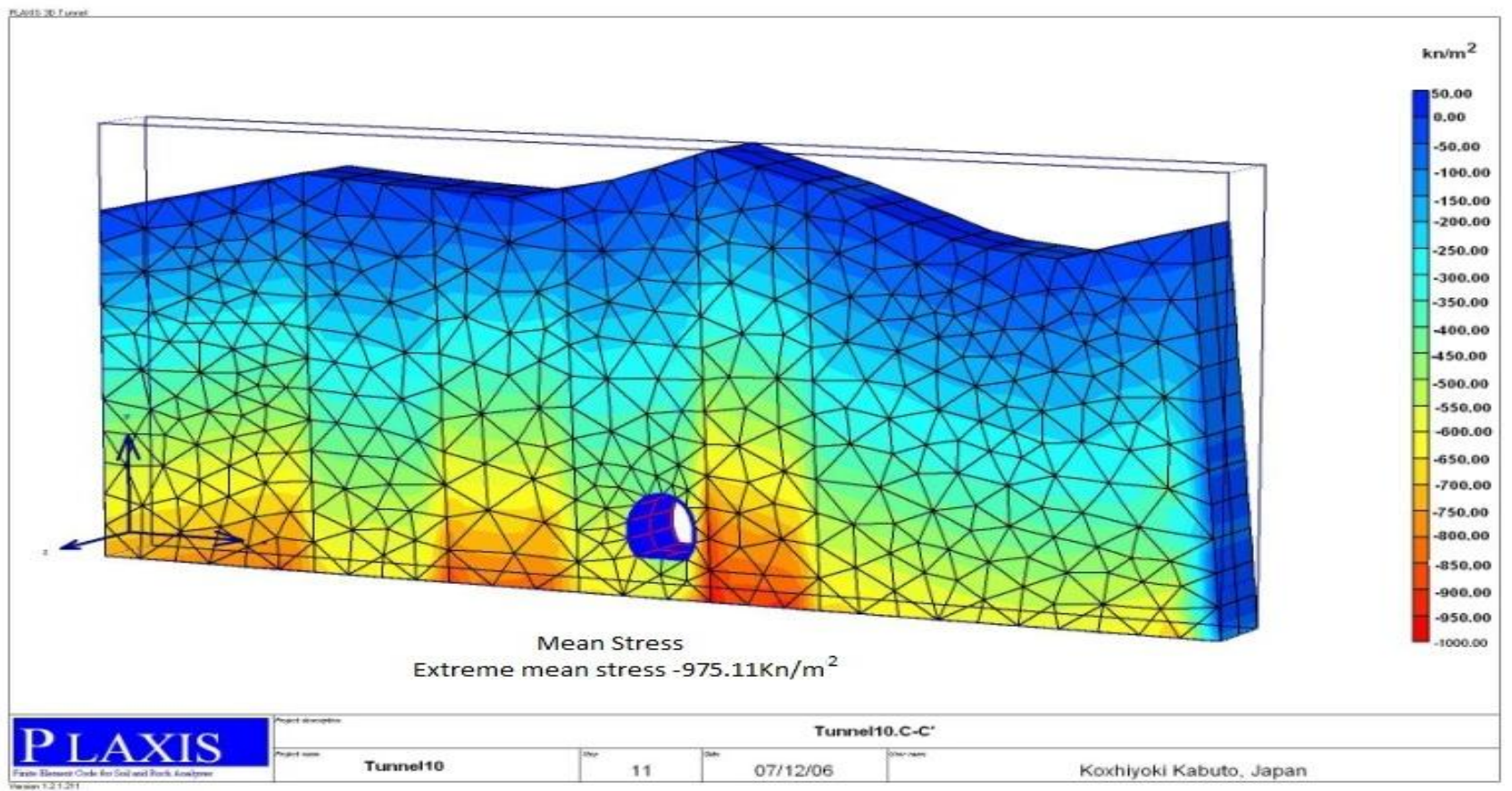

Figure 6. The stress distribution surrounding the tunnel in a cross section. 


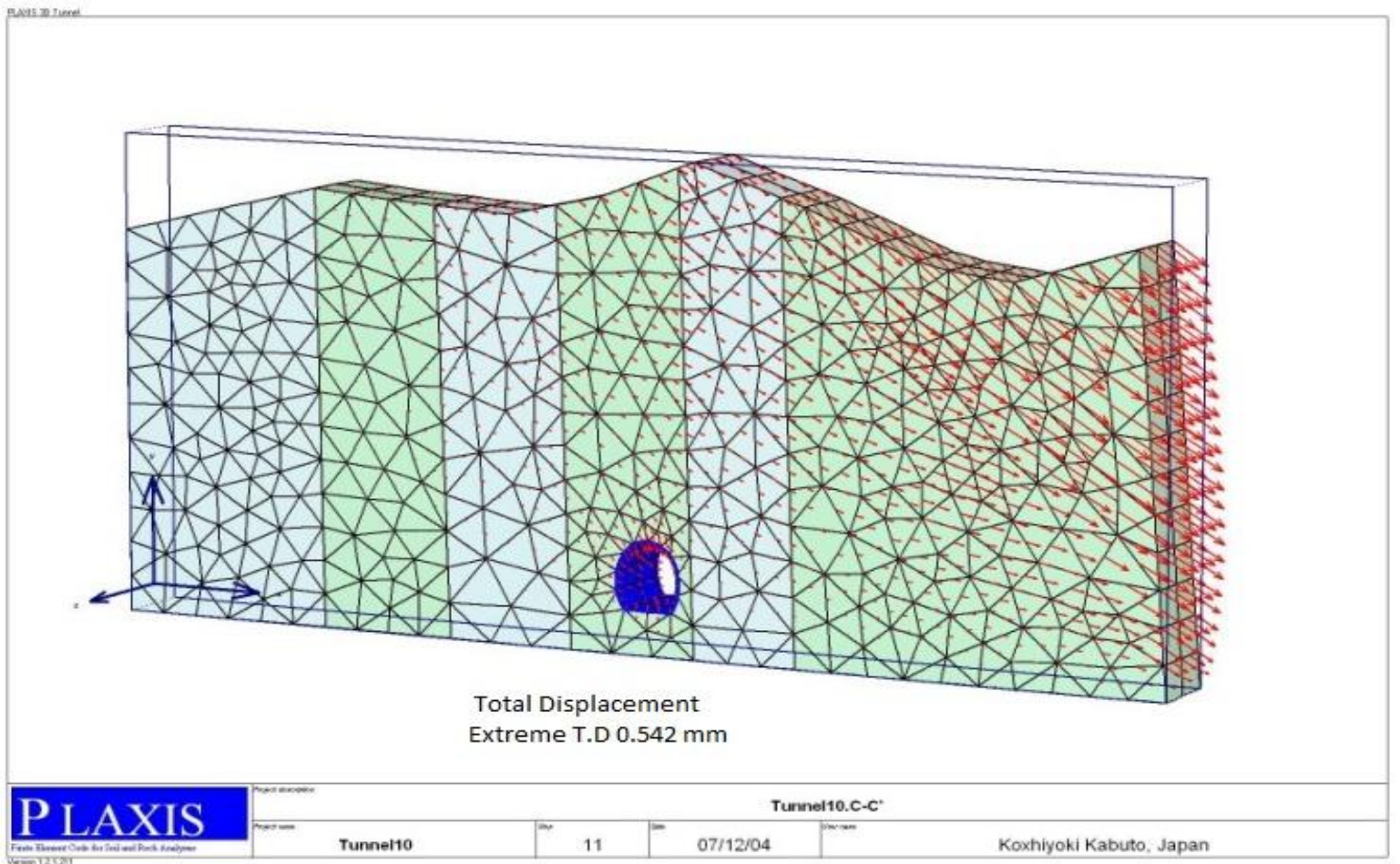

Figure 7. Total displacement of rock mass around the tunnel.

a)
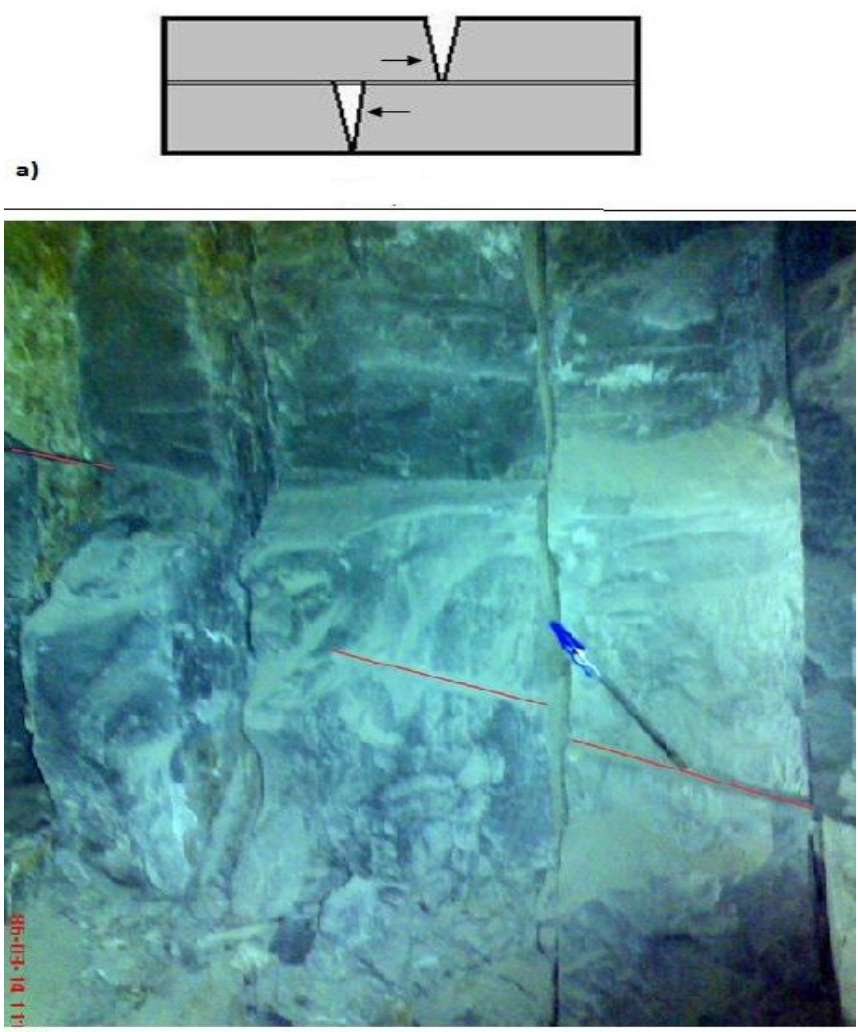

b)

Figure 8. Sliding of (a) step-over fracture and (b) step-over fracture in wall of tunnel.

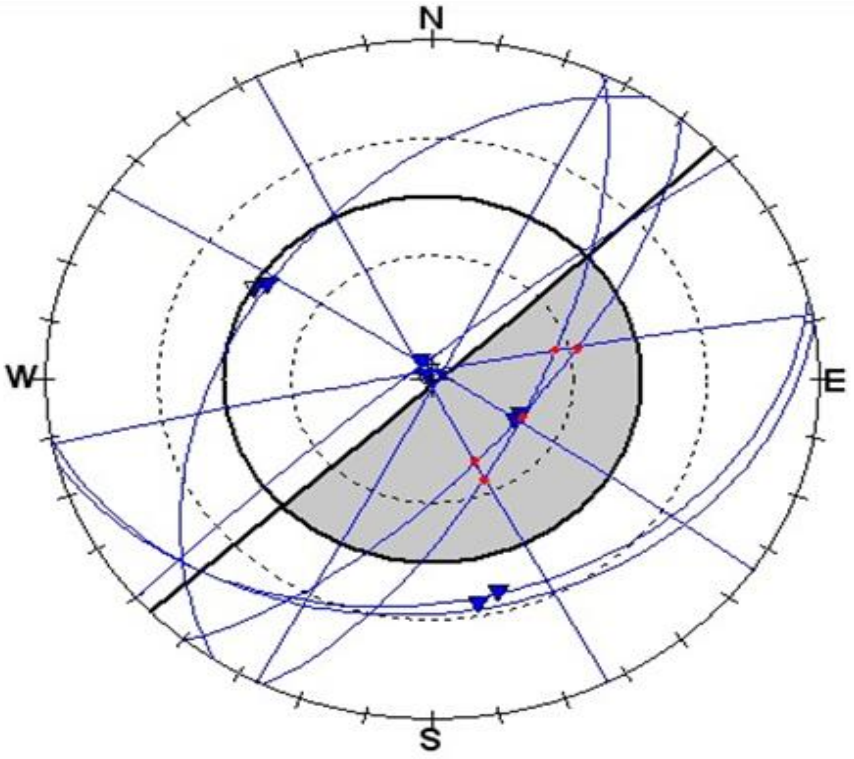

Figure 9. Analysis stability of rock blocks in tunnel wall.

\section{DISCUSSION}

However, there are several factors to analyze for the stability in rock tunnel, but many of them may seem simple and unimportant. Always, the most critical 


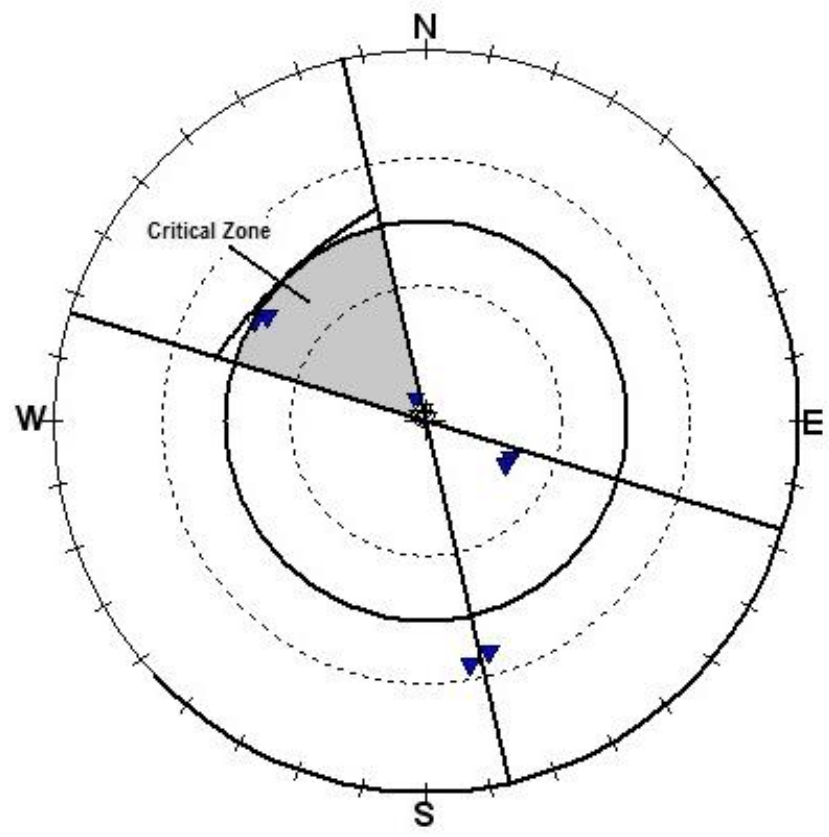

Figure 10. Analysis stability of rock blocks in tunnel roof.

parameters are not the most original ones. In the stability analysis of tunnel, suitable features have been recognized, but also, there are simple parameters to take into account.

It has been the aim of this paper to present the ability of simple parameters, such as joints and discontinuities in stability analysis of rock blocks in the tunnel. Moreover, there are so many researches about probabilistic models for analyzing rock block stability using joints features. The rock block stability is mainly dependent upon the characteristics of discontinuities; the random properties of discontinuities play a critical role in probabilistic analysis of rock stability (Park and West, 2000). The rock blocks generated from the joints are analyzed for their volume, height, perimeter, safety factor and probability of occurrence (Songa et al., 2001). The numerical analysis indicates that both the dip angle of joints and the lateral pressure coefficient have significant impacts on the failure mode and displacement characters of tunnel (Jia and Tang, 2008). In this case study, many characteristic of rock tunnel are estimated, and the results are shown. The outcomes of this survey will be demonstrated as follows:

1) The results of RQD and RMR show that the quality of rock is quite acceptable and the strength of rock mass can be stable.

2). Mainly, the analysis of stress and strain defines a normal distribution of stress, and small displacement in rock mass cannot have negative in stability.

3) Being the step-over, fractures between the bedding is considered to be an important factor in stability analysis of this tunnel. Fractures increase the risk of rock block movement, for creating more intersection points of discontinuities and more DSI.

Considerably, in this study, the discontinuity parameter as compared to other factors and serious effect of it has been studied. It shows that all the parameters in the analysis of rock block tunnel must be taken into consideration.

\section{Conclusion}

Results of stability analysis on the tunnel show that there are so many significant factors in this study. The importance of discontinuities in the stability of rock block in a tunnel in comparison with other parameters, have been investigated. Therefore, rock quality designation, rock classification, distribution of stress and displacements are estimated.

However, many parameters like RQD, RMR and stress and strain are suitable, but because of the increase of step-over fractures between the bedding and DSI increase in critical zone, the movement of rock blocks in the roof and wall will occur.

\section{REFERENCES}

Baecher GB, Einstein HH, Lanney NA (1977). Statistical description of rock properties and sampling. In: Proc., 18th U.S. Symp. Rock Mech., pp. 1-8.

Bieniawski ZT (1989). Engineering rock mass classifications. New York: Wiley.

Chan L, Goodman RE (1987). Predicting the number of dimensions of key blocks of an excavation using block theory and joint statistics, Proc., 28th U.S. Symp. Rock Mech., pp. 81-87.

Cooke ML, Underwood CA (2001). Fracture termination and step-over at bedding interfaces due to frictional slip and interface opening. $J$. Struct. Geol., 23: 223-238.

Goodman RE, Shi G (1985). Block theory and its application to rock engineering. Englewood Cliffs, NJ, Prentice-Hall, p. 338.

Hammett RD, Hoek E (1981). Design of large underground caverns for hydroelectric projects, with reference to structurally controlled failure mechanisms. Proc. Am. Soc. Civil Eng. Int. Conf. Recent Dev. in Geotechn. Eng. Hydro Projects, New York, ASCE., pp. 92-296.

Hoek E (2006). Practical Rock. Engineering, pp. 167-170.

Hoerger SF, Young DS (1990). Probabilistic prediction of key block occurrences. Proc. U.S. Symp. Rock Mech., pp. 229-236.

Jaeger JC, Cook NGW (1979). Fundamentals of Rock Mechanics. Third ed. Halsted Press, NY.

Jia P, Tang CA (2008). Numerical study on failure mechanism of tunnel in jointed rock mass. Tunnel. Undergr. Space Technol., 23: 500-507.

Lee Cl, Song JJ (1998). Stability analysis of rock blocks around a tunnel. Proc. Int. Conf. Mech. Jointed Faulted Rock ŽMJFR3, pp. 443-448.

Mauldon M (1993). Variation of joint orientation in block theory analysis. Int. J. Rock Mech. Min. Sci., 30: 1585-1590.

Park H, West TR (2000). Development of a probabilistic approach for rock wedge failure. Eng. Geol., 59: 233-251.

Songa JJ, Leeb C, Setoa M (2001). Stability analysis of rock blocks around a tunnel using a statistical joint modeling technique. Tunnel. Undergr. Space Technol., 16(Ž): 341-351. 